\title{
Experiências de Contacto dos Bebés com a Linguagem Escrita
}

\author{
Maria Fátima Moreira ${ }^{1}$ \\ Iolanda Ribeiro \\ Universidade do Minho
}

\begin{abstract}
RESUMO - Este estudo exploratório visa descrever as experiências de literacia de bebés entre os 14 e os 25 meses. Analisamse quatro questões, que experiências envolvendo a linguagem escrita no seio familiar são proporcionadas aos bebés, qual o valor que os pais lhes atribuem, como percepcionam o seu papel na promoção do desenvolvimento literácito dos filhos e como podem contribuir para o desenvolvimento da literacia dos mesmos. Adotou-se uma metodologia qualitativa, com recurso à análise de conteúdo categorial das respostas dadas por seis mães em entrevista individual e semiestruturada. Concluiu-se que estas mães valorizam e incluem nas suas práticas ações facilitadoras e de mediação de experiências de literacia por parte dos seus bebés, notando-se alguma variabilidade em função das respetivas habilitações académicas.
\end{abstract}

Palavras-chave: literacia emergente, literacia familiar, infância

\section{Experiences of Babies with Written Language}

\begin{abstract}
The purpose of this study is to characterize the literacy experiences ofbabies aged between 14 and 24 months. In this study, four issues were analysed: which type of written language experiences are offered to the children, how parents value these literacy experiences, the way parents perceive their own role in the literacy development of their children and what parents know about their means of contributing to the literacy development of their children. Six mothers were interviewed. These interviews were analysed with the use of a categorical content analysis. The results suggest that mothers value and include in their practices facilitative and mediation actions of literacy experiences with their children, noting some variability depending on the respective qualifications.
\end{abstract}

Keywords: emergent literacy, family literacy, childhood

Na convergência da investigação nos campos da literacia emergente, da literacia familiar e das teorias do desenvolvimento do conhecimento literácito, o contacto precoce com o impresso tem sido considerado como preponderante, bem como se tem salientado o facto de a qualidade das experiências de literacia, nas idades mais novas, depender em grande medida do meio familiar, designadamente das práticas educativas e do envolvimento parental.

A educação fundamentada no paradigma da literacia emergente baseia-se em três princípios nucleares: envolver as crianças na leitura e escrita desde o primeiro dia; criar um ambiente rico em material impresso, incluindo uma vasta variedade de linguagem escrita e tornar a linguagem escrita uma parte importante e funcional do quotidiano (Teale \& Sulzby, 1986).

Nas últimas décadas, o estudo do envolvimento parental para o incremento da literacia tornou-se, aos olhos dos académicos, políticos e investigadores num domínio chave para a educação e desenvolvimento das habilidades básicas (Benseman, 2002, 2003; Hannon, 2000; Mata, 2006; National Adult Literacy Agency, 2004; Sénéchal \& LeFevre, 2002). Salienta-se que, mais importante do que o número de livros em casa é aação mediadora da família em práticas como a de leitura partilhada, a leitura em voz alta e as atitudes positivas face à literacia no seio familiar, que influenciam

1 Endereço para correspondência: Escola de Psicologia, Universidade do Minho, Campus de Gualtar, Braga, Portugal. CEP: 4710-057. E-mail: iolanda@psi.uminho.pt significativamente a literacia nas crianças (Cochran-Smith, 1984; Morrow, 1995; Skage, 1995; Sonnenschein \& Munsterman, 2002; Taylor, 1983; Teale, 1984). Igualmente, são identificadas cinco áreas do funcionamento familiar como influenciadoras do desenvolvimento da leitura: o valor atribuído pelos pais à literacia, que pode ser manifestado através de comportamentos de leitura dos próprios ou comportamentos de encorajamento à leitura por parte dos filhos; a pressão para a realização, expressa através de manifestações das suas expectativas quanto à realização dos seus filhos, instrução na leitura e resposta a iniciativas de leitura e interesse; a disponibilização e uso instrumental de materiais de leitura (as experiências de literacia têm maior probabilidade de ocorrer em lares que possuem livros para crianças e outros materiais de leitura e escrita; as atividades de leitura com as crianças e, por último, as oportunidades para a interação verbal (Hess \& Holloway, 1984; Snow, Burns, \& Griffin, 1998). Nesta linha de ideias e tendo subjacente a perspetiva teórica da prática social, o modelo ORIM, proposto por Hannon (Hannon, Weinberger, \& Nutbrown, 1991; Hannon, 1995; Hannon \& Nutbrown, 1997, Hannon, 2000), integra quatro condições determinantes do desenvolvimento da literacia, a saber: oportunidades $(\mathrm{O})$ no dia a dia para a aprendizagem da leitura/escrita; reconhecimento (R) pelos outros das aprendizagens realizadas; interação (I) apropriada com os utilizadores da linguagem escrita; existência de um modelo (M) de utilizador da literacia. Aplicado à primeira infância, constituem-se como oportunidades de aprendizagem (O), o contacto da criança com atividades de desenho de rabiscos, com o impresso e a participação em atividades suscetíveis 
de a ajudarem a interpretar esse ambiente, tais como jogos de rimas e segmentação do oral, partilha de livros de estórias e outros materiais escritos, visitas, viagens, férias que tragam novas oportunidades de literacia. Por outro lado, o encorajamento dado à criança, reconhecendo e valorizando as suas pequenas realizações, como sejam o manuseamento de livros e leitura, ilustram a segunda condição do modelo (R). O envolvimento com a criança, explicando-lhe e desafiando-a a mover-se em relação a conhecer mais acerca da literacia, nomeadamente através da participação em atividades tais como voltar as páginas de um livro, escrever o seu nome num cartão de parabéns, constitui exemplo da condição (I). Por último, quando os pais agem como leitores/escritores perante a criança (ex. lendo jornais para obter informação ou para lazer, escrevendo notas ou listas de compras) funcionam como modelos $(\mathrm{M})$.

Tomando como pano de fundo este olhar sobre as práticas parentais de estímulo ao desenvolvimento da literacia, juntamente com trabalhos como os de Gadsden (1998) no âmbito das crenças parentais acerca deste fenómeno, o presente estudo incidiu nas experiências de literacia dos bebés do ponto de vista das práticas e conceções maternas. Partiu da formulação de quatro questões: que experiências envolvendo a linguagem escrita no seio familiar são proporcionadas aos bebés nos dois primeiros anos de vida? Qual o valor atribuído pelos pais às experiências de literacia dos seus bebés? Como percecionam os pais o seu papel na promoção do desenvolvimento literácito dos filhos? O que sabem os pais, ou pensam saber, acerca de como podem contribuir para o desenvolvimento da literacia dos seus filhos e dos meios que existem para os ajudarem nesta tarefa?

\section{Método}

\section{Participantes}

As mães entrevistadas $(n=6)$, provenientes de um meio essencialmente urbano, foram selecionadas de entre as participantes $(n=56)$ que, num estudo prévio (Moreira, 2007; Moreira \& Ribeiro, 2009), haviam indicado que, entre outros brinquedos e jogos, os seus bebés possuíam livros. As mães tinham profissões em diferentes áreas (técnica de serviço social, agente de viagens, enfermeira, operária fabril, cabeleireira e auxiliar de lar e centro de dia) com idades compreendidas entre os 29 e 37 anos, com diferentes níveis de Escolaridade ( $6^{\mathrm{a}}$ série, Ensino Secundário e Ensino Superior) e todas eram casadas. Dos bebés, três meninos e três meninas, apenas uma menina era filha única. Todos os restantes ocupavam o segundo lugar na fratria, estando as suas idades compreendidas entre os 14 e os 25 meses de idade.

\section{Procedimentos de Coleta e Análise dos Dados}

$\mathrm{Na}$ coleta dos dados recorreu-se a estudo qualitativo, apoiado em entrevista semiestruturada (ver Apêndice). A primeira parte da mesma foi direcionada para a pesquisa de informação acerca das experiências de literacia dos bebés, inspirando-se no modelo teórico proposto por Hannon (1995) para a definição das dimensões a explorar nas práticas parentais. Na segunda parte, dirigida para a pesquisa das representações e atitudes parentais acerca da literacia, visava-se dar ênfase à integração de dimensões internas aos indivíduos na compreensão do fenómeno da literacia, nomeadamente a relação existente entre significações/praxis.

Cada uma das entrevistas foi realizada de modo individual, por um único entrevistador, com registo audio e posterior transcrição. No momento inicial da entrevista explicitou-se o objetivo do estudo e garantiu-se a confidencialidade da informação. As entrevistas tiveram uma duração aproximada de 60 minutos e foram realizadas nos contextos indicados pelas mães (creche, casa e no trabalho).

\section{Resultados}

No tratamento dos dados optou-se pela técnica de análise de conteúdo, de tipo categorial (Bardin, 2004). No processo de categorização foram definidas dimensões de análise correspondentes às propostas pelo modelo de Hannon a que se juntou uma outra relativa às representações e conceções parentais. Para cada dimensão foi identificado um conjunto de índices que se agruparam em categorias e subcategorias, que se descrevem de seguida.

\section{Dimensão O: Oportunidades de contacto dos bebés com material de leitura e escrita}

Nesta primeira dimensão, as categorias emergentes referiram-se às características dos materiais de leitura e escrita com os quais os bebés contactam, ao como, ao quando e onde se processa o contacto, assim como ao interesse que os materiais de leitura/escrita despertam nos bebés.

Entre os tipos de materiais, os livros surgiram referenciados por todas as mães, ainda que nem sempre sendo de propriedade exclusiva do bebé, particularmente no caso dos que têm irmãos mais velhos: "ela nasceu já cheia de livros, os da irmã". As revistas, folhetos publicitários, jogos e brinquedos com letras foram referidos pontualmente, sobretudo pelas mães com níveis de habilitações mais elevados: "revistas sim, ela tem em casa e tenta folhear"; "publicidade da caixa do correio, dou-lhe mesmo para ela se distrair"; "tem um que tem números, que é aquele cubo de encaixar...letras, tem, tem...o quadro magnético, gosta de brincar mas não tem a perceção de que são letras, brinca por brincar". Algumas mães leem a partir de outros suportes, "nas caixas da papa, nos cremitos dela, também no champô, o iogurte...".

Os livros de cartão grosso foram os mais mencionados, ao que parece estar subjacente a preocupação de adequar o material à idade e ao tipo de manipulação do bebé: “... eu não a deixo brincar muito com o fino, que ela rasga-o com facilidade, então dou-lhe mais do grosso"; ou, "...próprios para a idade dele com umas folhas grossas, parece cartão, para ele poder mexer sem estragar". A referência a livros em materiais de ir à água surgiu mais relacionada com a variável nível sociocultural, só duas mães com habilitações superiores mencionaram este tipo de materiais:" de esponja, mas não é 
habitual; "tem livros na banheira". Ao contrário, uma outra disse: "não, mas também nunca vi disso". Apenas num caso foi indicada a utilização de livros de pano.

Os livros a que os bebés têm acesso incluem os relacionados com desenhos animados, "Noddy... Winnie the pooh", livros temáticos sobre "animais...cores" ou contos tradicionais, clássicos da literatura infantil: "casinha de chocolate... as Fábulas de La Fontaine...".

Quanto ao formato e ao código, os livros combinam imagens com palavras, "imagens e letras (a da galinha tem poucas letras, a da princesa e do gato das botas já tem mais) ...". Segundo a maioria das mães, os bebés interessam-se mais pelas imagens ("não mostra muito interesse pela leitura, quer é saber se é um boneco,..."; "acho que é pela imagem, acho que nunca me apercebi de ela olhar para as letras"; "vê as imagens, não é?"), particularmente as de personagens dos desenhos animados ou animais: "ele gosta muito de ver os desenhos, ..., olha para um lado, olha para outro, depois pede para folhear à maneira dele, que ele ainda não fala, mas pede". Apenas uma mãe faz referência ao interesse manifestado pelo conteúdo (mensagem) da estória: "às vezes começa a virar as páginas é, mas há livros de que ela gosta, por exemplo, o Peter Pan, ela gosta e então deixa-se estar...”.

A forma dos livros influencia, também, o interesse de alguns bebés: "são dois livros, um que tem a forma de um cão e outro que tem a forma mesmo do gato e as imagens não são desenho animado, é mesmo real,... é o que ela gosta mais, eu penso que é pela forma do livro".

A exploração dos livros processa-se de forma espontânea, "pode mexer livremente nos livros", ou subentendendo o cumprimento de regras e valores, como sejam os do respeito pela propriedade dos outros: "vai buscá-lo, tem os dela e outros da irmã, os da irmã ela não os pode estragar, os dela ainda os estraga". Registou-se, igualmente, a preocupação em distinguir a abordagem de puro entretenimento (livro como brinquedo) da abordagem do livro pelo livro (mensagem): “...vão buscar um da coleção que está no quarto...e depois voltam a pôr no sítio, porque não se pode andar com aqueles.... para brincar andam com os outros".

O contacto com livros ocorre em vários espaços, mas sobretudo na sala e no quarto de dormir: "onde quiser, qualquer espaço, mas principalmente na sala, no sofá...é o sítio onde gosta mais...ela brinca com eles em qualquer local,... na banheira brinca com livros". Ocorre em diferentes situações, salientando-se nas refeições e ao deitar. A situação de viagem surgiu referenciada pela negativa: "noutras situações não, por exemplo em viagem não...o que ele leva é sempre um boneco...".

A maioria das mães lê aos bebés antes do deitar, com exceção de uma que afirmou: "não tenho essa rotina, tanto posso ler como não". Uma outra referiu-se a esse ato como sendo decorrente do facto de ter de ler para a filha mais velha: "comecei a ler para a minha filha desde que o meu filho nasceu, porque ela achava que eu dava mais atenção ao irmão,...". A leitura do livro não é, necessariamente, efetuada para induzir o sono, “...não porque ela para já adormece facilmente... agora, antes de adormecer, todos os dias .... abrimos um livro para ela, ela pede mesmo, ... nem se esquece".

No decorrer das outras rotinas, a leitura é efetuada com diversas finalidades, para manter o bebé ocupado, distraído e mais colaborante (“...como ela gostava muito de livros, para conseguir dar-lhe de comer, ela ia vendo as imagens e eu ia-lhe dando de comer) ou associando, casualmente, intenções educativas: “...eu utilizo muito para entretê-la, enquanto ela come, um livro que é...os sentidos, o olfato, a audição,..., são livrinhos...em que tem vegetais, os vários meios de transporte,... outro que tem o corpo humano".

Relativamente às experiências fora de casa, nenhuma mãe já levou os seus bebés a bibliotecas. Parecendo incomodadas pelo facto, expressaram que tal se deve a dificuldades de tempo ("infelizmente não, acho que nisso não tenho tempo") ou a constrangimentos profissionais: "trabalho ao sábado, por isso não posso".

O momento do primeiro contacto com livros acontece sensivelmente entre os cinco meses e os 18 meses: "o primeiro que começou foi aos sete meses"; “...dela mesmo desde para aí os 5-6 meses"; "sei lá, devia ter cinco meses, mesmo pequenina"; "ele tinha um ano e qualquer coisita, para aí um ano e 4 meses". Uma mãe considerou que, antes do ano é muito cedo para ter livros: "dele mesmo não tem. O irmão teve ao ano e meio, fui eu que lhe comprei...porque antes do ano, acho que não tem assim aquela capacidade...para ver sim, mas não tem aquela capacidade.... É para estragar tudo...".

Excetuando uma mãe que afirmou não incentivar o filho a escolher ("não é incentivado a escolher..."), existe, na maioria das mães, a preocupação com o envolvimento do bebé na compra, permitindo-lhe que participe: "tinha uma prateleira com vários livros e eu,...tens aqui os teus livrinhos, escolhe um...não saem dali sem um livro"; "vê, sempre que eu vou comprar eu levo-os comigo". O conteúdo figurativo surgiu como o critério determinante da compra, tendem a adquirir livros apelativos pela imagem, mais do que pelo conteúdo: "a pensar quando fosse mais velhinha, aquelas estórias infantis que toda a gente tem, Pinóquio, Cinderela. Agora, os outros que é para ela realmente ver são mais simples, com muitos desenhos, mais para ela identificar os desenhos e as palavras"; "nesta fase preocupo-me mais com a imagem".

Os livros são arrumados "em local acessível, no quarto, baixinhos para ela os ir buscar" "“...os dela estão na sala, numa prateleira onde ela chega", "estão no quarto, à vista de olhos", “...no quarto de arrumações, ...e eu deixo-o lá brincar, ...sentado numa mantinha no chão e ele fica lá todo contente". Contudo, algumas mães introduzem certas restrições: "não estão de fácil acesso, mas eu abro o armário..."; "não tem acesso aos livros porque os livros da irmã estão juntos..., os da irmã têm aquelas páginas que rasgam".

Relativamente aos materiais de escrita com que os bebés contactam, englobam"livros de pintar,...lápis de cor...", folhas de papel soltas ou "tem um caderno". O acesso a este tipo de material é mais tardio do que o contacto com livros. A aquisição dos primeiros materiais situa-se, na generalidade, "depois do ano, 18 meses, antes era um bocadinho cedo, as preocupações eram outras", "teve esse caderno, não foi há muito tempo, talvez no Verão" ou "mais tarde que os livros, já tinha um anito". À semelhança do que se passa na compra de livros, observou-se a preocupação (pelo menos de algumas mães) em envolverem os filhos na compra: “...sempre que eu vou comprar eu levo-os comigo". 
O acesso ao computador foi indicado por duas das mães com grau académico mais elevado, ainda que em posições opostas. Uma referiu-se a um contacto em que há exploração ("no computador sabe que pode ver lá, mas é mais aqueles desenhos...já tentou mexer no teclado, mas interessa-se mais pelo desenho") e a outra não permite o acesso: “..., não tem contacto com o computador".

\section{Dimensão I: Interações pais - filhos em torno da linguagem}

Nesta dimensão as categorias encontradas descrevem o processo interativo entre Pais-bebés em torno de atividades que envolvam a linguagem escrita.

A leitura conjunta surge em diferentes idades dos bebés: “ já antes dos 18 meses", "pr'aí aos seis meses". Nos casos em que os bebés têm irmãos mais velhos, a leitura tende a englobar ambos: “... deitamo-nos as três. Primeiro leio para a irmã mais velha...e depois...pego no livro dela “; "leio pr'ós dois...". Por vezes o filho mais novo participa sobretudo como espectador: "comecei a ler para a minha filha desde que o meu filho nasceu,.. ele vai ficando ali enquanto eu leio".

Nas atividades de leitura atende-se ao ritmo pessoal do bebé: "não é obrigada a ouvir até ao fim...", "quando quer parar...deixo que pare;"...às vezes ficamos a meio porque ela quer ir buscar outro, é-lhe permitido isso, ...". Por outro lado, a alternância de papéis na manipulação de livros foi referida apenas uma vez ("ela quer que eu folheie o livro, outras vezes é ela que folheia..."), enquanto que a liberdade de escolha do material de leitura variou entre a total liberdade (em que "a criança... escolhe"), a liberdade relativa ("nunca lhe li uma estória com ela contrariada,...é a irmã que escolhe, influenciada por mim") e, finalmente, a impossibilidade de escolha: “...vou pegando num a cada dia, mesmo que ele diga eu não quero esse ou não quero aquele,...é um cada dia...eu prefiro que leia todos, ouça todos,..."

A postura do bebé durante a leitura passa por estar "sentado ao lado" do adulto, " no sofá" ou na cama, e pela adoção de diferentes atitudes: de escuta ativa ("ele gosta de ouvir..."); ou de escuta dispersa, "ainda não para a ouvir ler..., dá saltos em cima de mim, vai querendo tentar tirar o livro que eu tenho nas mãos, não está quieta......" " "tem dificuldades em focar a atenção".

A leitura é acompanhada da expressão dos afetos, nomeadamente através da troca de carícias: “...às vezes até encosta a cabecita, ...finge que se magoa no livrito só para lhe dar um beijinho e um miminho, ..."; “.... andamos as três sempre muito aos beijinhos"; "às vezes está a ler, começa a dar beijinhos, começa a fazer miminhos."; "ele gosta, encosta-se a mim, depois começa-me a mexer no cabelo". Todas as mães com um nível de habilitações mais elevado afirmam a ocorrência deste tipo de comportamentos. Nas outras mães, apenas uma refere este tipo de manifestações.

Relativamente ao método de leitura, foram identificados três, que designamos por observação comentada de livros, leitura simples e leitura guiada. O primeiro caracteriza-se pela pura manipulação dos livros, não existindo preocupação com a leitura: "brincar com livros, falar das imagens... abrir um livro para dizer, enumerar os animais". Na leitura simples, o adulto lê para a criança ("vou lendo só...ler e chamar a atenção com a mão para a imagem,...") e, eventualmente, respondendo a solicitações, ("se a criança pedir para repetir a página, repito...”). A leitura é expressiva e/ou dramatizada ("...imito as vozes, brinco na leitura...dou um pouco de emoção e imito o gato, miau e...canto, teatralizo os sons dos animais...").

A leitura guiada orienta-se mais para a instrução, nomeadamente de conceitos, apelando mais à participação do bebé. O hábito de fazer perguntas é frequente: “...este é a ovelhinha e este quem é? E ela não diz por exemplo vaca, que não consegue, mas imita os sons que identificam o animal e o som"; "perguntamos mas é a irmã mais velha que responde,..." ; “...leio e começo a perguntar porque é que eles fazem, porque é que são maus, porque é que eles comem outros animais";“...eu explico por outras palavras...".Nenhuma das mães apresentou preocupações em direcionar a atenção dos bebés para as letras ou palavras: "mais as imagens..., as letras nem tanto"; "não tenho por hábito apontar, seguir com o dedo a leitura"; “... letras não"; “... não comento as letras”.

Relativamente ao envolvimento de ambos os Pais em atividades de leitura partilhada, os relatos identificam certas diferenças em função do sexo. Em dois relatos foi dito que os pais participam de forma equivalente às mães na leitura: “...o pai participa de igual forma"; "o pai participa ativamente...". Por outro lado, certas mães justificaram a não participação arguindo complementaridade em função dos interesses de cada progenitor (" na leitura não, normalmente está a arrumar a cozinha, aliás ele não gosta tanto, eu não gosto de arrumar a cozinha...), ou da aptidão leitora: “...o meu marido também lê, só que, começam-se a rir e ele não consegue, e depois o filho, claro, tu não sabes, ..."

A maior parte das mães referiu-se à experimentação gráfica, embora variando no nível de permissão dado a esta atividade por parte dos filhos. Entre as mães com menor grau de habilitações, duas tendem a inibir este tipo de comportamento, por razões de segurança (“... ele gosta de riscar, mas eu não deixo...tenho medo que ele se magoe") ou por considerarem pouco relevante ("...porque na creche acho que já fazem essas experiências"). Uma outra é mais permissiva, referindo: "gosta bem, ..., até sarrabisca na parede e tudo, ...ora bem, ele é pequeno, eu ainda tou como o outro, como és pequeno...". No grupo das mães com mais habilitações, similarmente ao que surgiu para o contacto com livros, uma mãe permite a experimentação mas incute regras ("aqueles que há assim para pintar,...pega nos lápis..., os marcadores não são para ela, são para a mais velha, só pega nos lápis de cera e nos lápis pequeninos...") e uma outra ilustra como o comportamento de experimentação gráfica é de iniciativa do bebé: "risca espontaneamente...pede o papel...aponta...em casa pede, já sabe onde há os papéis, só quer papel branco, se tiver outro risco já não quer e sabe onde estão os lápis”.

\section{Dimensão R: Reconhecimento}

Partindo dos relatos em torno de atividades de leitura e de escrita, surgiram implícitas categorias descritivas da dimensão reconhecimento ou apoio às experiências de literacia espontaneamente iniciadas pelos bebés, distinguindo-se, 
especificamente, o reforço verbal e o não-verbal. No primeiro identificam-se os elogios e incentivos à realização, sobretudo face à produção gráfica: "ai que giro, faz outro, olha que bonito"; "que lindo, que giro". No reforço de tipo não-verbal, o desenhar com (“... ela procura para nós fazermos um desenho, ...pede, às vezes...um popó,...”) ou brincar junto, isto é, entrar na atividade: “...há outras alturas em que eu a vejo com o livro e vou lá e pego no livro e até leio, não faço isso todas as vezes..., mas sempre incentivo, ... acho importante...depende da minha disponibilidade...". Comportamentos como arquivar as produções gráficas, mais comuns nas mães com maior grau académico, são também apontados: "estão lá guardados, ...”; “....eu tenho os desenhos que ela me deu todos guardados na minha mesa-de-cabeceira". Finalmente, as atitudes/ações que, não sendo manifestações de reforço poderão, no entanto, atuar como tal: "não, eu não ralho, apenas pergunto o que é que vais fazer com eles...".

\section{Dimensão M: Pais enquanto modelos}

Nesta dimensão foram retratados comportamentos de leitura e de escrita, manifestados pelos próprios Pais na presença dos bebés.

Registou-se que todas as mães, com menor (“...leio pouco, ... mais ou menos dois livros por ano) ou maior frequência ("gosto muito de ler...leio mais ou menos um livro e meio por mês, onze livros por ano...nas férias não leio tantos") realizam atividades de leitura e de escrita. Estas têm finalidades diversas, a saber: formação ("... quando estive a tirar a pós-graduação, elas viam-me a estudar...” “.... ando a tirar a carta, tenho de estudar, passo para o cadernos"); fins profissionais ("é, e elas veem no computador, estamos no computador a trabalhar e, nessas alturas, eu sento-as... ali ao meu lado"); lazer ("pai lê o jornal...", “...leio, mais nas férias"; "...tenho um livro na minha mesinha-de- cabeceira e o meu marido também", "leio...romances"); e atividades da vida quotidiana, lista das compras ("vê...o mais velho diz logo, ah! Eu quero marcadores, quero livros, quero canetas...").

Relativamente à modalidade de escrita utilizada pelos Pais, foram referenciadas a escrita manuscrita e em computador, esta última referida por duas mães de nível académico mais elevado: “..., é mais com o pai, ela já presenciou a fazer relatórios".

\section{Dimensão RP: Representações parentais acerca da literacia}

Esta dimensão refere-se ao que as mães pensam, quer acerca das experiências de literacia precoces, quer sobre o impacto que estas podem ter na aprendizagem das competências de leitura/escrita e no desenvolvimento infantil, bem como o modo como percecionam o seu papel no propiciar de experiência aos filhos.

Relativamente à idade mais apropriada para o contacto com livros e materiais de escrita, uma mãe considerou que "...todas as idades têm de ter um acompanhamento, mas esta fase é muito importante" e deverá ser um contacto sem preocupação com a grafia, esta preocupação a existir deverá centrar-se nos conceitos matemáticos ("talvez esteja mais preocupada...com os números 1,2 , uma banana, duas bananas, ...”. Uma outra mãe pensa que o momento ideal será "a partir de um ano".

As mães associaram a importância do contacto com livros quer ao desenvolvimento do gosto pela leitura ("um motivo para que umas crianças gostem de ler e outras não poderá ser não terem tido muito contacto com esse tipo de material"), quer às aprendizagens escolares: “...às vezes até a aprendizagem, mesmo na escola, às vezes o tipo e a maneira como realmente falam sobre os livros, ... as experiências que têm...pode influenciar".

A utilidade da promoção de hábitos de leitura foi vista de diferentes modos: pelo impacto positivo no alargamento do vocabulário (“... para ela ir aprendendo... e... ter o máximo de vocabulário... acho muito importante estes hábitos de leitura, ...), bem como no desenvolvimento do gosto pela leitura (“... se eles tiverem cada vez mais cedo estas experiências acho que... vão gostar... é importante eles gostarem", "o contacto com os livros sim, acho extremamente importante... para... virem a ler e a gostar de ler", "a leitura é a base de tudo..."); como meio facilitador das aprendizagens que as crianças irão ter de fazer, quando entrarem na escola e no futuro (“... sei lá, talvez para aumentar a criatividade... ao ler vai-lhes abrir novos horizontes... serão, talvez, melhores em composições, .... do que crianças que só têm brinquedos, que não têm livros...", “... é importante que eles saibam qualquer coisa ..., uma pessoa se souber qualquer coisa é mais rápido de aprender"); como fator facilitador da adaptação à escola ("eu acho que se ela nunca tivesse livros e fosse agora para a escola,... chegava lá e era capaz de não ligar aos livros, ou não ligava ou então ficava abismada,... assim, ela já vai, já está habituada...”); como promotor do desenvolvimento cognitivo, nomeadamente da capacidade de atenção/concentração ("e acho que alimenta a concentração, o facto de a gente estar ali sentada a ouvir... isto é importante para tudo, para a escola...").

Apenas referida por uma das entrevistadas, a importância do contacto com jogos de letras surgiu apenas reconhecida para crianças em idade pré-escolar: "para a mais velha que para o ano vai iniciar a escola..."

O valor atribuído ao saber ler e escrever foi perspetivado, pelas mães, como fator de desenvolvimento, pessoal ou social. Na primeira condição, realçaram o papel do saber ler e escrever como estímulo para a procura de novos saberes ("ela ao querer ler vai querer saber novas coisas") e a leitura como instrumento indispensável à aquisição de novos conhecimentos em domínios diversificados: “... é a cultura, está interligado mas vai ajudar também na escrita, nos erros... acho, não só para o dia a dia..., acho que em todas as áreas é importante, a leitura, o enriquecimento... muito daquilo que nós sabemos é não só pela televisão, ... é através da leitura, ...., os jornais, as revistas..., as conversas que nós temos com as pessoas é muito influenciada por aquilo que lemos"; "o facto de ela querer saber ler, uma criança se gosta de ler... provavelmente não sei se será mais inteligente..., mas vai aprender mais coisas do que outra que não gosta de ler"; "é que se gostarem de ler, depois começam a ler, leem muitos livros, ficam com outra cultura geral, ...”. A importância da leitura para a aquisição de competências no domínio da 
comunicação interpessoal foi, também, focada, como é percetível na seguinte opinião, "eu acho que é importante, até para a personalidade, não é? saber escutar, ...".

A alusão à importância da literacia para o desenvolvimento social do indivíduo foi evidenciada sob duas óticas, a da sobrevivência e a da ascensão social. Observa-se a primeira em expressões do tipo, "eu acho que na sociedade de hoje isso é fundamental, claro que as pessoas podem na mesma fazer outras coisas, ..." ou "a leitura é a base de tudo". Quanto à ascensão social, encontra-se, ao contrário daquela, exclusivamente expressa no discurso das mães com nível de habilitações mais baixos e torna-se visível nos seguintes excertos: "gostava muito que eles tivessem um emprego que não tivessem de sujar as mãos, ..., a leitura pode ajudar a isto"; ".... tendo-se gosto na leitura, na escrita..., se calhar ter-se-á outro futuro,...”; “... é a gente, agora, que tem que estar a dizer: ai tem que estudar muito para ser isto,...".

No tocante ao papel de mediação dos pais nas experiências de literacia, foram os seguintes os objetivos que, segundo eles, deverão orientar o seu próprio comportamento: (a) Disponibilizar meios e recursos, tais como livros, materiais de escrita e até mesmo jogos ("dar-lhe a possibilidade de que consiga esses materiais..."); (b) Promover o gosto pelos livros, "habituá-los de tal maneira que eles gostem... é importante... tentar motivar, ...”, “... incentivá-los a gostar... acho que os pais têm um papel importantíssimo, se não ... eu acho que acabam por se desinteressar...”, “... a família é mais determinante no gosto pela leitura do que a escola..."; (c) Facilitar um clima relacional positivo nas atividades com livros ("... brincar, a criança tem que rir, temos que..., juntar a brincadeira à leitura e a criança acaba por pôr gosto na leitura"; (d) Atuar como modelos (" eu não preciso de dizer para ela ler porque elas ao verem-me a ler é porque deve ser uma coisa boa,..."; “... como vê fazer,... vai fazendo a mesma coisa..."); (e) Ler com os filhos. Sobre este aspeto, só uma mãe não considera estar condicionada pelo tempo (" “... dentro do tempo que é possível, consegue-se, normalmente consegue-se, ..."), três gostariam de ter mais tempo ("... é pouco"; "gostava de ter mais tempo"; "chego tarde, gostaria de ter mais tempo...") e uma outra atribui a responsabilidade desta indisponibilidade à vontade própria, dizendo: "é assim, não é tempo porque se a gente tiver vontade, o tempo arranja-se, ..., se calhar ... já está na pessoa...eu também já não trouxe muitas raízes porque eu não me lembro nunca dos meus pais terem brincado comigo nem com os meus irmãos"; (f) Acompanhar os filhos no processo de ensino-aprendizagem em colaboração com outros agentes educativos. Embora não se tenha registado consenso entre as mães relativamente a este objetivo, três destacaram a necessidade de atuarem em complementaridade com o Jardim/Escola e uma colocou de lado essa possibilidade, argumentando que "não, não consigo, nem eu tenho pachorra para isso, nem a gente está qualificada para isso", ainda que sem deixar de afirmar: "é claro que a gente também tem que ajudar, a gente também tem que puxar por eles...". Das restantes, uma distingue dois níveis distintos de intervenção em função do que se pretenda estimular/ensinar ("na aprendizagem das competências específicas de leitura e escrita... eu acho que deve ter mas aí muito com a Escola, com o Jardim..."), enquanto que outra considera que deve ser em simultâneo: “... quando no Jardim acharem que ele deve começar essa área, a família claro também deve ter". Por sua vez, uma outra mãe pensa que o papel dos Pais "é o de ajudar, porque é um trabalho da escola...", enquanto que outra interroga-se: “... nós temos que os ensinar, o que aprendemos e o que sabemos agora, não é?!’”.

Ainda no que se refere ao acompanhamento do processo de aprendizagem dos filhos, além do papel dos pais na promoção da literacia é também salientado o contributo das educadoras: "eu sei que a educadora lê todos os dias uma estória para eles, isso também já puxa um bocadinho e se eles levarem um livro para o Jardim, a educadora lê o livrito que eles levam, ... incentiva-os... a levar livros, não só brinquedos". Ilustra-se, assim, a importância dada à relação família-creche, também presente na afirmação,..."é importante a família, claro, mas a família sem a professora não faz nada".

A finalizar, as mães reportaram-se aos seus conhecimentos sobre práticas adequadas de promoção da literacia de modo pouco expansivo, não especificando. Se é certo que praticamente todas gostariam de saber mais sobre estes assuntos (“... gostaria de saber mais", “... de ter mais informação, ... aquilo que eu sei é aquilo que eu leio....”; “... de saber mais, ..."; “... sei alguma coisa... gostava de saber mais"; “... deveria saber mais"), quando falaram sobre como obter mais conhecimento, uma revelou o seu total desconhecimento ("não sei, não conheço") e as outras apenas nomearam possíveis fontes, tais como partilha de experiências com outros pais, recurso a profissionais da área da Educação (professores, educadores e psicólogos) ou à literatura.

\section{Discussão}

O primeiro objetivo neste estudo dirigia-se para a caracterização das experiências com a linguagem escrita, proporcionadas aos bebés nos dois primeiros anos de vida. Os dados mostraram ser comum os bebés terem acesso a livros infantis de conteúdo diversificado e a outros suportes. Este contacto ocorre precocemente, independentemente da condição sociocultural das famílias, contemplando a possibilidade de escolha e liberdade de manipulação por parte dos bebés. Os resultados vêm, assim, ao encontro de princípios nucleares do paradigma da literacia emergente: envolver as crianças na leitura e escrita desde o primeiro dia, criar um ambiente rico em material impresso e tornar a linguagem escrita uma parte importante e funcional do quotidiano (Teale \& Sulzby, 1986), bem como apresentam convergências com estudos que têm vindo a ser realizados com crianças pré-escolares (Lynch, 2009; Mata, 2006; Saracho, 1999, 2002; Sénéchal, 2006).

A maioria das mães realiza atividades de leitura com os bebés, embora seja mais regular nas mães com habilitações escolares mais elevadas. A exploração dos livros é essencialmente centrada nas imagens, incorporando a exploração de conceitos (animais, formas, cores) e sem preocupação em centrar a atenção do bebé no texto.

As situações de leitura ocorrem, predominantemente, durante as refeições e ao deitar. Menos frequente é a sua utilização durante o banho (livros de plástico colocados na banheira) e o envolvimento das mães quando a exploração 
do livro é iniciada pelo bebé. A adequação dos materiais à idade é uma preocupação generalizada e o incutir regras na utilização dos livros é preocupação de algumas mães.

O contacto com atividades precursoras da escrita é mais tardio e a sua experimentação tende a ser mais inibida, atitude justificada por questões de segurança. Os materiais proporcionados incluem papel, livros de pintar e lápis de cor. Alguns bebés contactam já com o computador.

É dada atenção ao ritmo e temperamento do bebé. As atividades de leituras ocorrem num clima afetuoso e são elogiadas as produções espontâneas. As mães afiguram-se como modelos de utilização da linguagem escrita, embora de modo pouco consistente. Várias das práticas referenciadas (ex. escolha dos livros e materiais de desenho pelos bebés, liberdade na sua manipulação) propiciam o desenvolvimento da motivação, do gosto pela leitura e pela escrita, porém as mães com menores habilitações literárias são mais diretivas e permitem uma menor liberdade aos bebés

Estas condições são essenciais à promoção do gosto da leitura. Encorajar os bebés a tomarem iniciativa na manipulação de um meio significativamente estimulante é ajudá-los a construírem o seu próprio conhecimento (Carter, Chard, $\&$ Pool, 2009). As crianças que em idades precoces tenham acesso a experiências frequentes, variadas e positivas com o impresso tornam-se mais conscientes deste sistema simbólico, das suas funções, bem como se interessam mais pela escrita e são mais motivadas para a leitura (Baker, Serpell \& Sonnenschein, 1995; Baker, Mackler, Sonnenschein, \& Serpell, 2001), sobretudo se a interação for qualitativamente significativa. Se os pais expressam uma atitude positiva perante a leitura e as crianças sentem que eles se implicam emocionalmente no ato de ler, então, elas próprias sentirão o desejo de aprender a ler (Martins, 1996, Sonnenschein \& Munsterman, 2002).

O segundo objetivo deste estudo dirigia-se para a caracterização das conceções das mães acerca do desenvolvimento da literacia e do seu papel na promoção desse desenvolvimento. As mães têm consciência da importância do papel da família para o desenvolvimento da literacia dos seus filhos. Proporcionar oportunidades de contacto com livros, ler com os filhos num clima relacional positivo são aspetos que as mães perspetivam como devendo fazer parte da sua prática, essencialmente pelo seu carácter promotor do gosto pela leitura e da aprendizagem.

Ainda na perspetiva das mães, ler assume dois significados: veículo de desenvolvimento pessoal (aquisição de conhecimentos, competências de comunicação) e veículo de desenvolvimento social, entendido por elas como instrumento de adaptação, meio de integração socioprofissional e de progressão social ou melhoria das condições de vida, sobretudo para as mães com menores habilitações. Tal constatação faz levantar a hipótese de que as mães com menores habilitações tendam mais a associar o desenvolvimento literácito a maior poder económico e a profissões mais reconhecidas e menos duras. Esta ideia surgiu igualmente já retratada nos trabalhos de Gadsden (1998), em que a literacia surge perspetivada como um possível meio de mobilidade social e de redução da pobreza.

A necessidade, expressa pelas mães, de obterem mais informação sobre como realizar atividades em torno da lei- tura adquire particular sentido em estudos que salientam o facto do conhecimento dos Pais acerca de estórias poder ser preditor em competências de vocabulário e compreensão oral de crianças pré-escolares (Cruz, \& Ribeiro, 2009; Sénéchal, \& LeFevre, 2001), apoiando a ideia de que a promoção de programas de literacia dirigidos aos pais poderá constituir-se como um meio importante no desenvolvimento da literacia das crianças, tornando-os mais seguros e intencionalmente comprometidos na promoção e no desenvolvimento literácito dos seus filhos, pois que a frequência e o modo de responder às questões das crianças pelos Pais influencia a capacidade de leitura, sobretudo se as mães detiverem conhecimentos sobre como se tornarem mais responsivas e dialogantes durante a leitura partilhada (Saracho, 2002; Sénéchal \& LeFevre, 2002)

Em 56 mães apenas 6 referiram a presença de livros entre os brinquedos dos bebés. $\mathrm{O}$ pequeno número de casos avaliados limita a possibilidade de generalização dos resultados, limitação esta que é inerente aos estudos de caso (Christensen, 2007). As práticas em torno da leitura descritas pelas mães são similares às encontradas em outros estudos com crianças em idade pré-escolar (Mata, 2006) sugerindo que os comportamentos e atitudes nos primeiros meses de vida da criança se prolongam nos anos da educação escolar. Fica por esclarecer se as mães que não incluem os livros entre os brinquedos dos bebés prolongam este para padrão nos anos seguintes ou se mudam iniciando as práticas de leitura e de escrita mais tardiamente. Adicionalmente a análise e caracterização das práticas de literacia familiar envolvendo bebés e das interações durante a leitura de livros, a análise das diferenças entre pais e mães, entre famílias de diferentes níveis culturais e a descrição das mudanças que variam ao longo dos primeiros 24 meses justificam a realização de estudos posteriores com um número alargado de participantes.

\section{Referências}

Baker, L., Serpell, R., \& Sonnenschein, S. (1995). Opportunities for literacy learning in the homes of urban preschoolers. In L. M. Morrow (Ed.), Family Literacy: Connections in Schools and Communities (pp. 236-252). Newark, DE: International Reading Association.

Baker, L., Mackler, K., Sonnenschein, S., \& Serpell, R. (2001). Parents' interactions with their first-grade children during storybook reading and relations with subsequent home reading activity and reading achievement. Journal of School Psychology, 39(5), 415-438.

Bardin, L. (2004). Análise de Conteúdo. Lisboa: Edição 70.

Benseman, J. (2002). Family Literacy in Manakau City: First formative and process evaluation report. School of Education, University of Auckland. Retrieved from http://www. lifelonglearning.co.nz

Benseman, J. (2003). Family Literacy Programmes Pilot Implementation: Interim (Second) Formative and Process Evaluation Report. Centre for Continuing Education, University of Auckland. Retrieved from http//www.lifelonglearning.co.nz.

Carter, D., Chard, D., \& Pool, J. (2009). A family strengths approach to early language and literacy and low-income African American pre-schoolers' skills. New Directions for Child and Adolescent Development, 92, 73-87. 
Cochran-Smith, M. (1984). The making of a reader. Norwood, NJ: Ablex.

Christensen, L. B. (2007). Experimental methodology. Boston: Pearson.

Cruz, J., \& Ribeiro, I. (2009). Práticas de literacia familiar em idade pré-escolar. In I. Ribeiro \& F. L. Viana (Eds.), Dos leitores que temos aos leitores que queremos. Ideias e projectos para promover a leitura (pp. 75-113). Coimbra: Edições Almedina, SA.

Gadsden, V. L. (1998). Family cultures and literacy learning. In J. Osbon \& F. Lehr (Eds.), Literacy for all-issues in teaching and learning (pp. 32-72). New York: Guilford Press.

Hannon, P. (1995). Literacy, home and school. London: Falmer Press.

Hannon, P. (2000). Reflecting on literacy in education. New York: Routledge Falmer.

Hannon, P., Weinberger, J., \& Nutbrown, C. (1991). A study of work with parents to promote early literacy development. Research Papers in Education, 6(2), 77-97.

Hannon, P., \& Nutbrown, C. (1997). Teachers use of a conceptual framework for early literacy education involving parents. Teacher Development, 1(3), 405-420.

Hess, R. D., \& Holloway, S. D. (1984). Family and school as educational institutions. In R. D. Parke (Ed.), Review of Child Development Research, 7: The Family (pp. 179-222). Chicago: University of Chicago Press.

Lynch, J. (2009). Print literacy engagement of parents from low-income backgrounds: Implications for adult and family literacy programs. Journal of Adolescent \& Adult Literacy, 52(6), 509-521.

Martins, M. A. (1996). Pré-história da aprendizagem da leitura. Lisboa: Instituto Superior de Psicologia Aplicada.

Mata, L. (2006). Literacia Familiar. Porto: Porto Editora.

Moreira, M. F. (2007). Experiências de literacia dos bebés entre os 0 e os 24 meses. (Unpublished master's thesis). Universidade do Minho, Portugal..

Moreira, F., \& Ribeiro, I. (2009). Envolvimento parental na génese do desenvolvimento da literacia. In I. Ribeiro \& F. L. Viana (Eds.), Dos leitores que temos aos leitores que queremos. Ideias e projectos para promover a leitura (pp. 45-73). Coimbra: Edições Almedina, SA.
Morrow, L. M. (Ed.). (1995). Family literacy: Connections in schools and communities. New Brunswickm, N. J.: Rutgers University.

National Adult Literacy Agency. (2004). Working Together: Approaches to family literacy. Ireland: NALA.

Saracho, O. (1999). Families' involvement in their children's literacy development. Early Child Development and Care, 153, 121-126.

Saracho, O. (2002). Family literacy: Exploring family practices. Early Child Development and Care, 172(2), 113-122.

Sénéchal, M., \& LeFevre, J. (2001). Storybook reading and parent teaching: Links to language and literacy development. New Directions for Child and Adolescent Behavior, 92, 39-51.

Sénéchal, M., \& LeFevre, J. (2002). Parental involvement in the development of children's reading skill: A five-year longitudinal study. Child Development, 73(2), 445-460.

Sénéchal, M. (2006). The effect of family literacy interventions on children's acquisition of reading. From Kindergarten to grade 3. New Hampshire: National Institute for Literacy.

Skage, S, (1995). A Practical Guide to Family Literacy-Definitions and discussions. Family Literacy Action Group Alberta. Retrieved from http//www.nalds.ca/CLR/Pgfl/page 6-9.htm

Sonnenschein, S., \& Munsterman, K. (2002). The influence of home-based reading interactions on 5-years-old's reading motivations and early literacy development. Early Childhood Research Quarterly, 17, 318-337.

Snow, C. E., Burns, M. S., \& Griffin, P. (1998). Preventing reading difficulties in young children. Washington, DC: National Academy Press.

Taylor, D. (1983). Family literacy: The social context of learning to read and write. Exeter, $\mathrm{NH}$ : Heinemann.

Teale, W. H. (1984). Reading to young children: Its significance for literacy development. In H. Goelman, A. Oberg \& F. Smith (Eds.), Awakening to literacy (pp. 110-121). London: Heinemann.

Teale, W. H., \& Sulzby, E. (Eds.). (1986). Emergent literacy: Writing and reading. Norwood, $\mathrm{NJ}$ : Ablex.

Recebido em 21.05.2012

Primeira decisão editorial em 29.11.2013

Versão final em 22.05.2014

Aceito em 22.05.2014 


\section{Apêndice \\ GUIÃO DE ENTREVISTA}

Práticas e representações parentais/experiências de literacia de bebés entre os 4 e os 24 meses

Versão para investigação

\begin{tabular}{|l|}
\hline PARTICIPANTE \\
Data de nascimento (mãe) \\
Habilitações literárias (mãe) \\
Estado civil (mãe) \\
Profissão (mãe) \\
$N^{o}$ de filhos \\
Posição do bebé na fratria \\
Data nascimento bebé \\
idade \\
Bebé ao cuidado (mãe)
\end{tabular}

\section{PARTE 1: PRÁTICAS PARENTAIS}

BLOCO A - OPORTUNIDADES (O): Questões dirigidas para a exploração das práticas parentais orientadas para a criação de oportunidades de contacto com livros ou outro material escrito.

1. Com que brinquedos o seu bebé brinca habitualmente?

2. De entre esses brinquedos, há alguns que sejam livros?

3. Em que material são feitos?

4. São de que tipo? (contos, dicionários de imagens, formas, animais,...)

5. O seu filho pode mexer-lhes livremente? Deixa-o à vontade para mexer nos livros.

6. Tem por hábito dar livros ou outro material escrito ao seu bebé para ele brincar?

7. Onde é que o seu filho brinca com livros? Em todos os locais? (ex. no banho?)

8. Como e onde estão arrumados? É fácil ao bebé chegarlhes sozinho?

9. Nota que ele tem algum preferido?

10. Para além dos seus próprios livros, o seu filho tem tido possibilidade de contactar com outro tipo de livros ou de informação escrita (ex. livros dos irmãos, idas à biblioteca, a livrarias, jornal, revistas,... jogos com letras soltas ou outros; sinais)?

11. Que idade tinha o seu filho quando teve o seu primeiro livro? Quem lho comprou?

12. Que preocupações/critérios costuma ter ao escolher os livros para o seu bebé?
13. Para além de livros, o seu bebé costuma brincar com materiais de escrita (papel, lápis de cor, ...)

14. Acha que ele gosta de pintar/garatujar?

15. Como o faz? (porque o incentiva, espontaneamente, ....)

16. Foi sempre assim, ou tem notado diferenças?

17. Quando é que lhe ofereceu os primeiros materiais de escrita? (lápis, cadernos,...).

18. Leva-o consigo a comprar os livros e /ou materiais de escrita?

BLOCO B- INTERAÇÃ OES (I): Questões dirigidas para a exploração do tipo (qualidade e quantidade) de interações existentes entre os Pais e o bebé em atividades com livros e outros materiais/informação escrita.

19. Quando cuida do seu filho, por exemplo quando lhe dá banho, na alimentação, na muda a fralda, é habitual falar para e com ele?

20. Que tipo de "coisas" lhe diz? Costuma falar das cores, das formas,...? Porquê?

21. Responde às suas lalações?

22. Costuma cantar-lhe?

23. Passa algum tempo com ele a brincar com livros, a falar das imagens, das letras? Porquê?

24. E a ler? Tem por hábito ler para o seu filho?

25. Que idade tinha o seu filho quando the leu pela primeira vez?

26. Em que momentos lhe costuma ler e com que intenção (para quê e porquê)?

27. Durante quanto tempo? Com que frequência?

28. Que tipo de livros lhe costuma ler?

29. Existe algum motivo particular para a opção por determinado tipo de livros e não outros? (ex. não gostar de contos tradicionais; os mais à mão; preferências do bebé,...)

30. Quem escolhe os livros que lê ao seu filho?

31. Permite-lhe escolher os livros que ele quer ver/ ou quer que lhe leia?

32. Repete a leitura se for esse o desejo dele?

33. Como é feita a leitura?:

- Só por si, ou ele também participa?

- Senta-o no seu colo?

- Afaga-o, dá-lhe carinhos?

- Lê o nome do autor, do título?

- Vai apontando com o dedo as palavras?

- Permite-lhe que acompanha visualmente o texto e as imagens, que faça perguntas?

- Explora as figuras?

- Segue a leitura com o dedo por baixo?

- Coloca-lhe questões sobre o texto?

- Teatraliza? (gestos, sons - onomatopeias).

34. Como reage o seu filho à leitura?

35. Quando ele desvia a atenção, se interessa por outro objeto, ... o que faz? Insiste para que preste atenção, interrompe a leitura,...?

36. Para além de livros, tem por hábito ler para o seu filho outro tipo de materiais? (ex. nome das papas, pacotes de leite, publicidade na rua,...) 
37. Preocupa-se, ou tenta, ensinar o nome das letras associadas, por exemplo, ao seu nome ou a outros objetos?

38. E o seu marido participa também nestas atividades? Em que medida? (é mais do tipo de brincar do que de ler, raramente brinca com o bebé, não tem por hábito cuidar dele...)

BLOCO C- RECONHECIMENTO (R): Questões orientadas para a pesquisa de comportamentos parentais utilizados como reconhecimento/reforçadores da ação exploratória dos filhos, facilitadora do desenvolvimento da literacia.

39. Quando o seu filho pega num livro para brincar, apoia de algum modo esse comportamento (questiona-o, bate palmas, diz muito bem, olha que giro, faz-lhe perguntas, interrompe o que está a fazer para ver com ele o livro)

40. Mostra interesse pelas suas produções gráficas (garatujas, sarrabiscos,...), ou antes pelo contrário zanga-se?

41. Quando manuseia um livro, revista, tenta que o mantenha em bom estado? De forma muito rígida ou permitindo alguma flexibilidade?

42. Mostra-se contente quando ele tenta imitar comportamentos de leitura ou desenho/escrita? Ou quando ele lhe pede (de algum modo) que lhe leia?

BLOCO D- MODELAGEM (M): Questões orientadas para a exploração do papel assumido pelos pais enquanto modelos no uso das competências de literacia.

43. No seu dia a dia, realiza tarefas de leitura na presença do seu bebé? (ex. quando ele brinca, quando está com outra pessoa).

44. Quer descrever que tipo de tarefas? (literatura, relatórios ou outros documentos relacionados com a atividade profissional, faturas da luz, água, cheques, roteiros, livros de receitas)

45. Considera importante para o seu filho que ele o observe a si ou a outras pessoas (ex. irmãos) a realizar tarefas que envolvam leitura e escrita? Porquê?

\section{PARTE 2: REPRESENTAÇÕES PARENTAIS ACERCA DA LITERACIA}

46. Estivemos a falar sobre leitura/escrita com bebés, o que pensa acerca deste tema?

Continuando esta entrevista, gostaria, agora, de lhe colocar um conjunto de questões mais gerais, relacionadas com a aprendizagem da leitura e escrita:

47. Em seu entender, antes da entrada para o $1^{\circ}$ ciclo para que serve a leitura com e para a criança? (para nada?; apenas para entreter, para alargar o vocabulário?; simplesmente porque gosta de ler?)

48. Relativamente à aprendizagem da leitura/escrita, qual a importância que acha que estas competências têm ou irão ter na vida do seu filho? (num futuro próximo, no
Jardim de Infância, ou mais longínquo, quando entrar para a escola, um dia mais tarde)

49. Esta é uma questão com a qual ainda não se preocupa? ou, antes pelo contrário, preocupa-o desde os primeiros meses?

50. Qual pensa que deve ser o seu papel, enquanto pai/ mãe na aprendizagem da leitura e escrita do seu filho?

51. O que pensa que pode fazer para ajudar o (s) seu (s) filho (s) a aprenderem um dia a ler e a escrever?

52. Quando pensa ser a idade ideal para as crianças iniciarem a aprendizagem da leitura e da escrita? Só a partir dos 6 anos, entre os 3-6 anos ou ainda mais cedo?

53. Em sua opinião, quais os fatores que influenciam a aprendizagem da leitura e da escrita?

54. Algumas crianças gostam de ler outras não, na sua opinião a que se devem estas diferenças?

55. Pensa que é importante e possível ensinar as crianças a gostarem de ler?

56. Para si, o gosto pela leitura e escrita relaciona-se mais com as experiências que a criança tem no seio familiar ou com as que tem na escola?

57. Considera-se uma pessoa informada acerca do modo como pode contribuir para desenvolver o gosto pela leitura do seu filho ou gostaria de saber mais acerca deste assunto?

58. Gostaria de dispor de mais tempo para dedicar a atividades de leitura com o seu bebé, ou o tempo de que habitualmente dispõe é suficiente? Por que razão?

\section{PARTE 3: FINALIZAÇÃO}

Finalmente, e para si, que espaço ocupam ou que importância têm a leitura e a escrita na sua vida:

59. Gosta de ler e/ou escrever? ou nem por isso, lê apenas por obrigação (ex. profissional; resolução de problemas do quotidiano-preenchimento de impressos....)

60. Que tipo de leitura prefere?

61. Quantos livros lê, em média, por ano?

Para concluir, gostaria de colocar alguma questão ou fazer algum comentário sobre o que estivemos a falar?

\section{Agradeço a sua colaboração e o tempo dispensado.}

